Revista de Economia Política, vol. 34, no 2 (135), pp. 266-283, abril-junho/2014

\title{
A persistência da indexação no Brasil pós-Real
}

\section{ANDRÉ RONCAGLIA DE CARVALHO*}

The persistence of indexation in Brazil post-Real.

The paper analyzes the shortcomings of the Real Plan combining political science and economics, considering evidences on difficulties in implementing a complete plan of deindexation, namely: the distributional conflict, the corporatist relations between the State and society and the bureaucratic isolation of a highly specialized technocracy. The announcement of the plan triggered defensive reactions, fueling distributive tensions during the URV period, forcing the economic team to take measures that contradicted the overall guidelines followed. The persistence of indexation mechanisms indicate the resulting obstacles in seeking a reform of the State through a stabilization plan, even though the latter has the former as a precondition.

Keywords: Real Plan; distributional conflict; indexation; statecraft; stabilization. JEL Classification: N40; H19; C14.

\section{INTRODUÇÃO}

A inflação é um dos traços mais profundos da realidade econômica brasileira ${ }^{1}$ e resulta de um impasse social quanto à repartição do produto nacional (Bacha, 1987), o qual se transmuta em conflito distributivo. O fenômeno não é peculiar ao Brasil, e já foi amplamente abordado na literatura internacional. Todavia, a contri-

\footnotetext{
* Doutorando em Economia do Desenvolvimento — IPE-USP. E-mail: andre.roncaglia.carvalho@usp.br. O autor agradece os comentários e sugestões dos professores Pedro Garcia Duarte, Gilberto Tadeu Lima, Renato Perim Colistete, Jorge Eduardo de Castro Soromenho, dos colegas Joelson de Oliveira Sampaio, André Mountian e Lucas Squarize Chagas, bem como dos dois pareceristas anônimos dessa revista. Os erros e imprecisões remanescentes são, como de costume, de inteira responsabilidade do autor. Submetido: 29/abril/2013; Aprovado: 23/julho/2013.

${ }^{1}$ Em retrospecto, de 1980 a 1994, ano em que se inicia o Plano Real, o Brasil teve quatro moedas, cinco congelamentos de preços, nove planos de estabilização, 11 índices para medir a inflação, 16 políticas salariais diferentes, 21 propostas de pagamento da dívida externa e 54 mudanças na política de preços. No total, foram 30.000.000.000\% de inflação acumulada ao longo de 15 anos (Franco, 2005).
} 
buição brasileira ao inventário de experiências inflacionárias reside nos mecanismos institucionais desenvolvidos para lidar com o impasse social, a chamada indexação de contratos.

Em 1964, quando da implementação do Plano de Ação Econômica do Governo (PAEG) foi criado o instituto jurídico da correção monetária, por meio das ORTN's, que davam aos títulos públicos atratividade econômica no contexto de um ambiente inflacionário. Enquanto a prática permanecia localizada em alguns setores, bem como a política salarial mantinha os salários sob controle, a indexação se revelou um arrojado instrumento de convivência pacífica com a inflação (Simonsen, 1970, 1995). No entanto, em prazo mais longo, gestava-se o embrião da hiperinflação. A sequência de choques de oferta e de demanda ocorrida ao longo das décadas seguintes deflagrou o mecanismo potencializador que residia na prática indexatória, a qual perpetuava a memória inflacionária, estabilizando a velocidade de elevação de preços, tornando-os rígidos para baixo.

Neste sentido, a pedra de toque do Plano Real consistia em eliminar essa memória inflacionária por meio do atrelamento total dos ativos e preços da economia a um indexador geral, a URV, seguido pela desindexação plena a partir da conversão total de todos os contratos para a nova moeda, proibindo-se a utilização de qualquer mecanismo de indexação para contratos de prazo inferior a um ano. Obteve-se, assim, um limite inferior para o prazo de reajuste de contratos, buscando neutralizar a componente inercial da inflação.

O sucesso do plano foi imédiato. Celebrou-se o fim da inflação, muito embora o arranjo institucional da política econômica que dava suporte à estabilidade configurasse um equilíbrio muito delicado. A sensibilidade desse aparato exigiu dos formuladores de política econômica uma postura vigilante e flexível, de sorte a orquestrar respostas consistentes aos desafios criados por uma economia dotada de persistente memória inflacionária. A taxa de inflação caiu de forma consistente, ao longo do tempo, a patamares de um dígito, sustentando-se em baixos níveis, com exceção feita a conjunturas específicas, em que choques de diferentes ordens levaram a temporárias acelerações dos índices de preços, na segunda metade da década de 1990 e início dos anos 2000.

Em 1999, já no segundo mandato de Fernando Henrique Cardoso, um novo arranjo de política econômica é apresentado à sociedade. O Programa de Estabilização Macroeconômica (PEM) consistia em um tripé formado pela busca de austeridade fiscal, um regime de câmbio flutuante e a adoção do sistema de metas de inflação. Formulado com o apoio do Fundo Monetário Internacional, sob os auspícios de um socorro cambial, o programa centralizou a gestão macroeconômica na taxa de juros, instrumento fundamental da política monetária, em lugar da taxa de câmbio que, até então, servira de variável-chave para o controle da inflação (Bogdanski et al., 2000).

Destarte, a sintonia fina da política monetária obteve sucesso no controle do ritmo inflacionário, mantendo os índices de preços dentro das metas estipuladas na maior parte da década dos anos 2000. A controvérsia em torno do patamar das metas de inflação, na casa dos $4 \%$ ao ano, revela, entretanto, que se, por um lado, 
a inflação está sob controle, há, por outro, uma resistência à redução de seu patamar balizador. Com efeito, a política monetária tem sido bem-sucedida em estabilizar não a moeda, mas a taxa de inflação, o que poderia, intuitivamente, ser atribuído a algum resíduo de indexação. Mantido aparentemente em suspensão pelos mais de 15 anos, desde o início do Plano Real, o comportamento indexatório que se generaliza indica que o adestramento da cultura inflacionária brasileira foi um objeto de desejo das sucessivas equipes econômicas que não se realizou em sua plenitude. Dessa forma, é sugestiva a afirmação, ainda que preliminar, de que o arcabouço institucional que se formou a partir da implementação do Plano Real redefiniu as formas de manifestação e de conciliação do conflito distributivo e, como consequência, sedimentou as bases para a consolidação de uma trajetória da inflação com resistência à queda. ${ }^{2}$

O problema passou recentemente a ocupar as atenções da imprensa especializada e das autoridades governamentais, surpresas com o comportamento altista dos índices de preços e sua resistência às medidas de controle monetário. Três são os argumentos apresentados para explicar a inflação no período pós-Real: (1) o arranjo institucional representado pela indexação residual deixada pelo Plano Real, adicionando um componente inercial; (2) choques de oferta, associados à resposta monetariamente expansionista dos países desenvolvidos para combater os efeitos da crise financeira norte-americana inaugurada em 2007, bem como à elevação espantosa dos preços dos bens primários no mercado internacional, refletindo os ajustes estruturais no cenário internacional que orbitam em torno da consolidação da China como novo polo econômico; e (3) choques de demanda engendrados pela política econômica expansionista, ao longo dos dois mandatos do presidente Luiz Inácio Lula da Silva (Delfim Netto, 2011).

O presente trabalho focará a causa institucional supracitada, a qual recoloca o problema da indexação de contratos na pauta da agenda pública nacional, assunto curiosamente deixado de lado paulatinamente nos anos seguintes ao Plano Real, e oferece um interessante tema à teoria econômica do desenvolvimento e à historiografia econômica brasileira. Neste sentido, busca-se aqui uma abordagem histórica ao problema da indexação, tentando-se delinear as condições de viabilidade política da estabilização. Adota-se a hipótese de que a visão de curto prazo subjugou as possibilidades de estabilidade de longo prazo, invertendo-se a ordem do receituário tradicional de estabilização defendido pelos órgãos internacionais como o Fundo Monetário Internacional (FMI) e o Banco Mundial, qual seja, a máxima "put the institutions right first", para então, “put the prices right” (Sola, Kugelmas \& Whitehead, 2002, p. 13). O caso brasileiro mostra que conjunturas sociais críticas se impõem sobre os receituários teóricos, reclamando destes uma ágil adaptação.

\footnotetext{
${ }^{2} \mathrm{O}$ tema foi abordado recentemente na literatura acadêmica, tal como em Segura-Ubiergo (2012), em que se discutem os motivos da elevada taxa de juros no Brasil. À persistência da prática da indexação e seu efeito sobre a inércia inflacionária atribui-se importância secundária.
} 
Aventa-se aqui a possibilidade de que os aspectos históricos e, por conseguinte, de ordem política impediram a completa extinção do mecanismo da indexação. O conflito distributivo enraizado na estrutura social brasileira, combinado com o modelo de desenvolvimento econômico adotado ao longo do século XX (até a década de 1990), criou uma cultura inflacionária que, na década de 1980, atingiu o paroxismo hiperinflacionário, ainda que represado pelos sucessivos planos de estabilização heterodoxos, tornando a estabilização dos preços pré-condição para as reformas estruturais. Observa-se, assim, um paradoxo: a credibilidade das instituições é crucial para a confiança na moeda, ao mesmo tempo em que as reformas que garantem tal credibilidade são obstadas pelo ambiente de instabilidade monetária. ${ }^{3}$

O resultado é, como se pretende evidenciar, uma reforma monetária deficiente e incompleta, como argumenta Dornbusch (1997). Uma reforma monetária completa exigia, paradoxalmente, a efetivação de reformas institucionais que tinham na própria estabilização de preços a condição mesma para o seu sucesso.

\section{INDEXAÇÃO E INÉRCIA INFLACIONÁRIA NO PÓS-REAL}

É indiscutível que o Plano Real tenha reduzido o patamar da inflação a níveis baixos, quando comparados aos dados historicamente observados no Brasil, como mostra o Gráfico 1. A linha de tendência (polinomial) no gráfico indica uma suave ascensão ao final do período. Todavia, o nível da inflação permanece elevado quando cotejado aos níveis dos países desenvolvidos, além de apresentar forte resistência à queda - a qual se nota na constância das metas de inflação na casa dos 4,5\% a.a., adotadas pelo Conselho Monetário Nacional (CMN). Como resultado, o que se nota é um padrão crescimento-inflação diferente daquele comumente encontrado em outros países. O Gráfico 1 relaciona as duas variáveis, para o período 1996-2012. Note-se que o patamar inflacionário de longo prazo tende a permanecer acima da taxa de crescimento de longo prazo.

\footnotetext{
${ }^{3}$ A compreensão histórica desse "momento crítico" que é a implementação do Plano Real é crucial para validar o esforço subsequente de pesquisa sobre o tema. Duas etapas auxiliares complementam o argumento apresentado neste artigo e serão empreendidas em trabalhos posteriores. A primeira diz respeito a uma adaptação do "modelo de realimentação inflacionária", como preconizado por Simonsen (1974), ao arranjo institucional prevalecente na economia pós-Real, apoiando-se em modelos de conflito distributivo que incorporem a dinâmica intersetorial da economia, como a relação entre os preços de bens comercializáveis e não comercializáveis, bem como a relação entre preços de bens industriais, serviços e bens com preços monitorados. Adicionalmente, uma análise quantitativa do período pós-Real pode oferecer alguma compreensão a respeito da dinâmica da indexação a partir de alguns fatores, tais como: nível de cobertura e organização da estrutura sindical, abrangência da indexação dos contratos públicos e da dívida pública, taxa de avanço da produtividade do trabalho (esse elemento entra como uma variável de "hiato do produto"), inércia inflacionária, comportamento dos markups etc.
} 


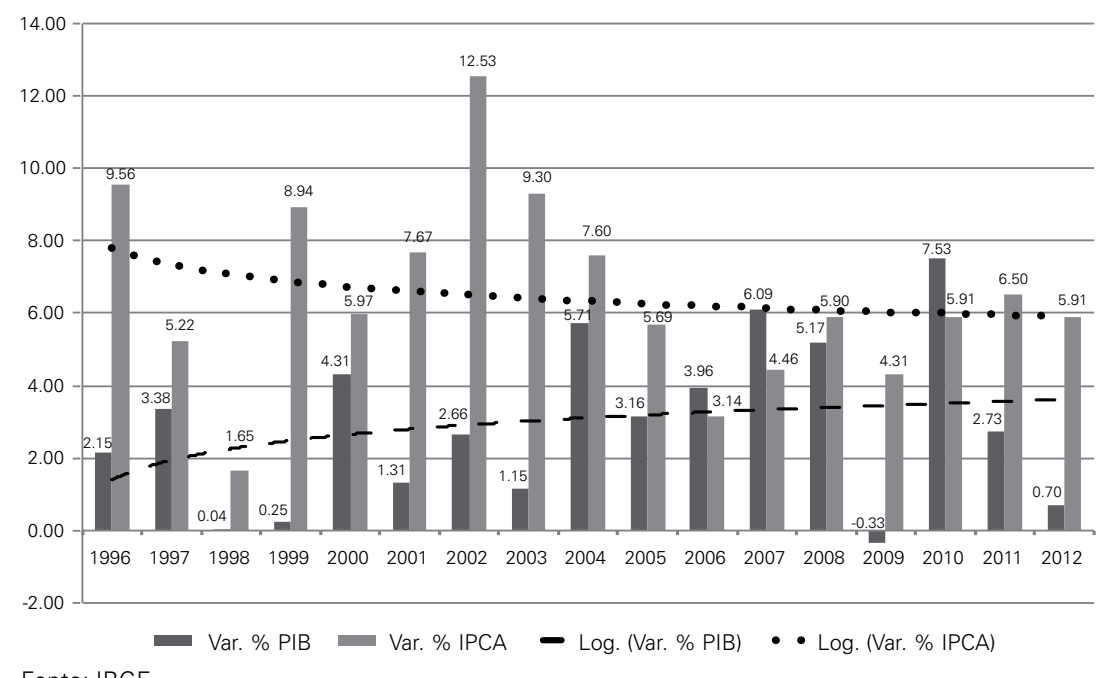

Fonte: IBGE.

A explicação para esse comportamento não é encontrada na literatura econômica, a qual não encontrou qualquer relação clara entre essas duas variáveis, tanto em longo quanto em curto prazo (Bruno \& Easterly, 1996). Uma hipótese plausível é que a persistência da indexação no período pós-estabilização contribua com a rigidez dos preços para baixo, gerando custos maiores à desinflação de preços, como reconhecido por Segura-Ubiergo (2012). Como se sabe de longa data, o mecanismo não ameaça a estabilidade econômica na ausência de choques temporários de oferta, muito embora deixe a economia mais sensível a choques de demanda ou de alterações estruturais no funcionamento da economia, como mostrado nos trabalhos clássicos de Gray (1976) e Fischer (1977). Infelizmente, esse assunto tem recebido uma atenção apenas pontual por parte da literatura econômica brasileira, abrindo-se uma lacuna a ser explorada. Senão vejamos.

No modelo de decomposição do Índice de Preços ao Consumidor Amplo (IPCA) — calculado pelo IBGE e que serve de indicador das metas de inflação - apresentado pelo Banco Central do Brasil em seu Relatório de Inflação (Banco Central do Brasil, 2011). São consideradas normalmente quatro variáveis explicativas, a saber: (1) variação cambial; (2) inércia inflacionária; (3) expectativas; e (4) inflação dos preços administrados. É interessante notar como o Banco Central tem captado esta inércia inflacionária em seus modelos macroeconômicos que guiam a política monetária. Sua metodologia de cálculo consiste em inferir o grau de persistência da inflação a partir da "parcela da inflação que excedeu a meta, acumulada a partir do último trimestre do ano anterior" (Banco Central do Brasil, 2011, p. 99). O modelo de cálculo da inércia adotado pelo Banco Central foi proposto Freitas, Minella e Riella (2002, p. 10).

$$
\mathrm{I}_{t}^{\mathrm{g}}=\left(\pi_{t-1}-\pi_{t-1}^{*}\right) \cdot \mathrm{C}_{\text {inércia }} \cdot \mathrm{W}_{\text {grupo }}
$$


$\mathrm{I}_{t}^{\mathrm{g}}$ sendo o efeito da inércia da inflação do ano anterior sobre a inflação do primeiro trimestre no ano corrente, estimado para um grupo $g ; \pi_{t-1}$ e $\pi_{t-1}^{*}$ denotam, respectivamente, a inflação observada e a meta de inflação no ano anterior; $\mathrm{W}_{\text {grupo }}$ representa o peso do grupo (livres ou administrados) no IPCA; e $\mathrm{C}_{\text {inércia }}$ representa o coeficiente de repasse da inflação do trimestre anterior sobre o trimestre corrente, tendo sua metodologia de cálculo omitida (o relatório apenas indica que seu valor é atribuído de acordo com as estimativas feitas pelo Banco Central). O efeito total da inércia é obtido, então, pelo produtório dos efeitos da inércia estimada em todos os grupos de preços (livres e administrados).

Esta medida de inércia representa tão somente um repasse da inflação que excedeu a meta para o trimestre seguinte, isto é, um carry over de inflação entre dois trimestres. ${ }^{4}$ A persistência dos efeitos da inflação do trimestre anterior pode ter tendência tanto declinante, uma vez extinta a pressão sobre um grupo localizado de preços, quanto ascendente, no caso de uma mudança estrutural que implique, na visão do modelo, choques persistentes de oferta ou de demanda. Além disso, fica sem menção a arbitrariedade com que se define da meta a ser atingida. Este procedimento pode, por si só, transmitir ao presente a memória inflacionária acumulada em períodos anteriores (a chamada prefixação), conferindo um piso para a prática da indexação (Franco, 2005, p. 283, nota 40). Assim, o que excede a meta é, em verdade, o que excede o piso estabelecido para a inflação. A metodologia expressa, portanto, uma autorregressividade embutida no modelo, na medida em que a meta estabelecida reflete o piso histórico da inflação recente, tornando o nível de inflação resistente à queda.

Convém notar que o conceito de inércia adotado na metodologia do Banco Central, cujo parentesco se encontra na chamada "nova síntese neoclássica" (Goodfriend e King, 1997), difere sobremaneira do conceito original de inércia inflacionária, apoiado no processo de realimentação, como desenvolvido por Simonsen (1974, 1995), Modiano (1983), Lopes (1985) e Resende (1985). A literatura econômica não oferece, até o presente momento, uma explicação para essa transição conceitual. Por outro lado, uma série de trabalhos empíricos com diferentes orientações teóricas vem tratando do problema da persistência inflacionária, ainda que a devida distinção conceitual entre "persistência" e "inércia" não seja feita claramente. Fasolo e Portugal (2003) constatam, a partir de uma curva de Phillips não linear para a economia brasileira, uma elevada persistência da inflação brasileira para o período 1990-2002, concluindo pela presença de uma componente inercial autônoma. Tombini e Alves

\footnotetext{
${ }^{4}$ Nos modelos econométricos estimados, a inércia é setorialmente captada e denota a propagação dos choques não explicados sobre a inflação do próprio segmento em questão. Isso se deve à dificuldade de decomposição do IPCA, dada a presença de forte multicolinearidade com a expectativa de inflação do Relatório Focus do Banco Central, o que dificulta a identificação do impacto de cada variável (inflação passado e inflação esperada, por exemplo) sobre o comportamento do índice de preços (cf. Martinez \& Cerqueira, 2011, p. 33).
} 
(2006) utilizam uma curva de Phillips híbrida para analisar a dinâmica dos preços livres do IPCA no período 1996-2006. Adotando estimação por filtro de Kalman, os autores apontam que os preços livres respondem à inflação passada, tendo o coeficiente de repasse sofrido uma redução em 1999, porém, recuperando-se em parte depois de 2002. Figueiredo e Marques (2009) corroboram a tese de existência de inércia inflacionária no Brasil e atribuem o fenômeno a um processo de longa memória embutida nas séries de dados. Na mesma linha, Tejada e Portugal (2001), Campêlo e Cribari-Neto (2003), Cribari-Neto e Cassiano (2005) e Araújo e Santos (2004) demonstram os efeitos permanentes de impulsos inflacionários (ou deflacionários) sobre a trajetória de longo prazo da inflação brasileira.

A presença de persistência inflacionária pode ser fruto de uma gama numerosa de elementos. Dentre eles, cumpre destacar a presença de rigidez de preços, de falhas informacionais, da possibilidade de indexação de contratos, a adoção de uma política fiscal permanentemente expansionista e, finalmente, a ocorrência de choques adversos - oriundos do setor externo, por exemplo - , os quais volatilizam a taxa de câmbio, causando impactos transitórios sobre os preços da economia.

Mesmo que todas essas forças incidam sobre a economia brasileira, a possibilidade de indexação foi considerada, pela equipe econômica, a principal fonte de pressão contínua sobre os preços. Nesse tocante, o Plano Real ofereceu uma resolução incompleta do problema inflacionário, a saber: 18 anos após a edição do Plano Real, a indexação persiste em aproximadamente $24 \%$ dos preços que compõem o IPCA-IBGE, os quais representam os preços administrados (basicamente, serviços de utilidade pública) (Banco Central do Brasil, 2012, pp. 94-101). Quando tomados todos os bens que apresentam contratos indexados formais, a parcela sobe para $38 \%$ da composição do IPCA-IBGE (Valor Econômico, 2012). ${ }^{5}$

É evidente que a estratégia do plano de promover a desindexação por meio de decretos não logrou solucionar as causas do conflito distributivo que alimentavam a memória inflacionária, a qual se cristaliza institucionalmente na prática da indexação. É sugestiva, ainda que pouco desenvolvida, a ideia de que, no Brasil, a inflação concorre com o mercado na regulação da atividade econômica que (Singer, 1988). Essa regulação pela inflação teria predominado até 1994, quando foi editado o Plano Real. A partir daí, sua importância foi reduzida, porém, permanece presente, tendo como expressão a indexação formal e informal de preços à inflação passada.

Assim, tendo em mente a relevância atual do tema para gestão da política econômica no Brasil e a lacuna existente na literatura acerca da alteração no conceito de inércia inflacionária, é imperioso lançar-se a uma revisão do arcabouço teórico que dá suporte à reflexão sobre esse tema.

\footnotetext{
${ }^{5}$ Para uma breve avaliação empírica da disseminação recente da prática da indexação no Brasil, ver Kirsten (2013).
} 


\section{MODELO FORMAL DO CONFLITO DISTRIBUTIVO E DA INÉRCIA INFLACIONÁRIA}

Toda inflação crônica é eminentemente um processo inercial e na raiz deste encontra-se o "conflito distributivo" (Lopes, 1985), o qual se caracteriza por um processo intertemporal de defesa da renda real por parte dos agentes econômicos. Taylor (1983) oferece o trabalho clássico da abordagem neoestruturalista, partindo de premissas mais próximas à realidade dos países subdesenvolvidos. Essa vertente da teoria econômica desempenhou papel relevante na demarcação do debate acerca do desenvolvimento econômico dos países da América Latina. São trabalhos que combinam diferentes ponderações e ênfases acerca dos conceitos de conflito distributivo, indexação e inércia inflacionária. André Lara Resende $(1979,1985)$ propõe uma teoria da inflação como resultado de um impasse social, tendo o conflito distributivo por causa motora da inflação, a partir de um "hiato de incompatibilidade" entre as parcelas da renda nacional demandadas por capitalistas e trabalhadores. O esforço clássico nessa linha é de Rowthorn (1977). Ademais, são referências importantes os esforços de Bresser e Nakano (1984), Lopes (1985), Modiano (1983, 1985, 1988), Arida e Resende (1986), Bacha (1987), Giambiagi (1988), Fraga Neto (1985), Franco (1995), dentre outros. Mais recentemente, Lima e Setterfield (2008) e Vera (2005) oferecem uma abordagem pós-keynesiana ao problema do conflito distributivo, enquanto Barbosa (2013) apresenta a visão tipicamente estruturalista, na linha seguida por Taylor (2004).

É a partir dessa linhagem de modelos que o pensamento econômico brasileiro apresenta importantes contribuições ao entendimento das experiências de inflação elevada e sustentada vivida por diversos países ao longo da história econômica do século XX. Em resumo, a incompatibilidade da renda nacional com o somatório das aspirações dos grupos sociais desencadeia um processo de recomposição sequencial de sua parcela na renda real.

A título de ilustração, pode-se formalizar o conflito distributivo - qual seja, a resistência dos grupos econômicos à erosão de sua renda real — por meio da análise de um "hiato de aspiração", definido como a diferença entre o padrão de vida e o estado em que vivem as pessoas e o nível ou padrão que elas gostariam de ter. ${ }^{6}$ Em termos de renda agregada nacional,

\footnotetext{
${ }^{6}$ Essa expressão remete diretamente aos autores da Teoria Clássica do Desenvolvimento. Celso Furtado definiu o subdesenvolvimento como a deformação socioeconômica em que o estilo de vida das economias industriais penetrava no perfil de consumo da sociedade com maior intensidade do que o fazia no aparelho produtivo. Com isso, a aspiração dos agentes econômicos era incompatível com a estrutura produtiva da economia. Esse hiato foi usado por Furtado para explicar a dependência da periferia com relação ao centro do capitalismo. O que se busca aqui é correlato ao esforço de Furtado, porém, em um plano diverso, a saber: mostrar que a aspiração da renda dos grupos sociais tem uma dinâmica diferente da capacidade de atendimento destas por parte da economia. Esse descompasso encontra resolução por meio da inflação. Além disso, Albert Hirschman e Ragnar Nurkse se afiliavam à ideia de que a inflação em economias pouco desenvolvidas estava associada a um suposto "efeito demonstração", segundo o qual a "atração exercida sobre os consumidores de países subdesenvolvidos
} 


$$
Y=W+P+F
$$

ou seja, o produto nominal $(Y)$ é o resultado do somatório da massa de salários $(W)$, da massa de lucros $(P)$ e da renda bruta recebida pelos proprietários de outros fatores que não trabalho e capital $(F)$, tal como rendas, royalties e pagamentos de juros. Cada grupo formula uma aspiração nominal de renda, dada por

$$
Y c=W c+P c+F c
$$

Supõe-se, por simplicidade, que $F=F c$, deixando $Y-F$ disponível para a distribuição entre trabalhadores e capitalistas no setor privado. Adotando-se o conceito de conflito como um estado de incompatibilidade entre os planos de ação de dois ou mais agentes, pode-se defini-lo formalmente pela razão $A=(Y c / Y)$, com $0<A<\infty$, que denota a proporção entre o total de demandas sobre a renda disponível, ou seja, o hiato de aspiração. ${ }^{7}$

É importante ressaltar que as demandas dos agentes econômicos sobre a renda nacional são moldadas, negociadas e reguladas por meio de arranjos institucionais, tais como complexos padrões de regras de precificação, estruturas de negociação entre patronato e sindicatos, fatores de poder de mercado e de burocracia, bem como indexação e outras cláusulas contratuais que definem a oportunidade de os agentes obterem ajustamentos de preços relativos quando da queda de sua renda abaixo de suas aspirações.

Com base na definição de $A(=Y c / Y)$, podemos notar que o conflito resulta de dois fatores: da elevação da renda desejada e da queda na renda disponível dos agentes. $\mathrm{O}$ desenrolar do processo dependerá da habilidade e do desejo dos agentes de exercer seu poder sobre a renda nacional ao longo do ciclo. Isso imprime um caráter adverso e não linear sobre relação entre salários e preços ao longo do ciclo econômico, tornando imperativa a consideração de aspectos como poder de mercado e concentração de mercado na explicação dessa relação. ${ }^{8}$

Adicionalmente, é válido analisar o problema do desenvolvimento como uma relação dinâmica entre o produto a que aspira a sociedade e o produto efetivo. Inspirando-se no modelo de Baumol (1967), pode-se formalizar a dinâmica do hia-

pelo padrão de vida elevado dos países envolvidos e pelos bens ali disponíveis faz com que aqueles desejem os frutos do progresso econômico; não os prepara, porém, para os sacrifícios indispensáveis à sua obtenção" (cf. Hirschman, 1961, p. 236).

${ }^{7}$ Com efeito, a premissa básica da abordagem da inflação como conflito é que para valores de A maiores que a unidade, os preços subirão mais rapidamente do que o antecipado pelos agentes econômicos em suas demandas ex ante, estabelecendo-se as condições para a inflação. Nessas circunstâncias, a inflação não antecipada em qualquer período é a consequência direta do desequilíbrio entre as demandas $e x$ ante e a renda disponível ex post.

\footnotetext{
${ }^{8}$ Por exemplo, o desemprego pode ser inflacionário sempre que a concentração de mercado ocasionar ajustamento no mark-up com vistas a manter a taxa de lucro. Isso significa que não se pode tomar por anomalia a coexistência de inflação e desemprego, sendo esse resultado um produto do comportamento normal da interação entre firmas e trabalhadores. Para uma análise mais detalhada, ver Vera (2005).
} 
to de aspiração da renda. Suporemos que tanto a renda desejada (Yc) quanto a renda efetiva $(\mathrm{Y})$ crescem cumulativamente ao longo do tempo. Formalmente, temos

$$
\begin{aligned}
& Y c=Y_{0} \cdot e^{r t} \\
& Y=Y_{0} \cdot e^{g t}
\end{aligned}
$$

de forma que $A=(Y c / Y)=1$, se $r=g$. Se $r>g$, temos um $A>1$, o que significa acirramento do conflito, haja vista que o produto não cresce no ritmo desejado pela sociedade, dando-se o inverso se $g>r$. Nesse último caso, porém, o conflito pode dar lugar a um excesso de oferta, o qual pode implicar estagnação ou crescentes superávits comerciais, a depender das elasticidades das exportações em relação à renda mundial e aos preços dos bens, abrindo as portas para a análise pós-keynesiana de crescimento restringido por balanço de pagamentos.

A persistência dessa dinâmica distributiva propicia o desenvolvimento de mecanismos que neutralizem os efeitos nocivos da inflação, tais como a indexação, a correção monetária etc. A indexação é, portanto, um mecanismo de conciliação do conflito distributivo, por meio do qual a inflação decorrida em um dado período, registrada por um índice de preços, é repassada para o preço presente, de forma a repor o poder de compra da moeda que a elevação geral dos preços corroeu. Trata-se da substituição da moeda legal como unidade de denominação do valor nominal dos contratos por outra unidade de conta, cujo valor, definido nos termos da moeda legal, vem a definir as condições de liquidação da obrigação (Carvalho, 1994, p. 109). Enfim, "a indexação institucionaliza a espiral preços-salários" (Simonsen, 1995, p. 5).

Quando este mecanismo se torna generalizado, os contratos passam a embutir em si uma memória inflacionária, de sorte que medidas anti-inflacionárias convencionais de controle da demanda agregada (ditas “ortodoxas") perdem eficácia, além de acirrar as disputas distributivas entre grupos sociais. ${ }^{9}$ Tomemos a contribuição de Mário Henrique Simonsen (1995, pp. 129-130), por meio do seu "modelo de realimentação inflacionária". Pode-se formalizar o comportamento inercial da inflação, supondo-se uma economia com indexação plena de salários. Resumidamente, temos uma relação entre a taxa de inflação $\pi_{t}$ no período $t$ e a variável $k_{t}$, a qual expressa a capacidade da economia de pagar o salário real de acordo com os parâmetros distributivos da estrutura social. A queda, manutenção ou aumento no valor desta variável conforma situações que podem levar, respectivamente, a aumentos, manutenção ou queda da inflação, segundo a relação

\footnotetext{
${ }^{9}$ Parece ter sido esse o temor que levou o governo Castelo Branco a regulamentar a correção monetária apenas como cláusula de exceção, sujeita de análise caso a caso, de sorte a evitar a "multiplicação desordenada das células de indexação" evitando-se, assim, a aceleração da inflação. Todavia, nas palavras de Simonsen (1995, p. 4), o governo comete o pecado original da ciência política, ao legislar sobre aquilo que é tido apenas como exceção. Com efeito, ao incorporar explicitamente a correção monetária à política econômica, o governo envia um sinal a toda a sociedade, a qual passa a emulá-lo, alastrando-se, lentamente, o estatuto da correção monetária por toda a sociedade, uma vez que a incapacidade governamental de gerir suas próprias contas impunha severa imprevisibilidade sobre as futuras taxas de inflação, contra o que a indexação é o remédio indolor.
} 


$$
\pi_{t}=\left(\pi_{t-1}-k_{t}\right) /\left(1+k_{t}\right)
$$

Supondo-se o equilíbrio distributivo neutro $\left(k_{t}=0\right)$, tem-se a manutenção do salário real ao longo do tempo, de sorte que a inflação presente seja dada pela inflação passada. ${ }^{10}$ Em termos dinâmicos, seria plausível considerar que a inflação se inicie com um choque de oferta, tal como uma deterioração nos termos de troca no setor externo ou uma desvalorização real da taxa de câmbio. Os eventos desta ordem deprimem o salário real que a economia é capaz de pagar $\left(k_{t}<0\right)$, gerando demandas por reposição de renda, via aumentos nos salários nominais, os quais levam a uma inflação ainda maior. A inflação temporária se torna inflação permanente, uma vez que qualquer tentativa de manter o salário real por meio de indexação é automaticamente frustrada pela inflação que resulta do reajuste dos salários nominais. Por outro lado, deduz-se da relação supracitada a conclusão de que uma aceleração no crescimento do salário real tende a reduzir a inflação, como teria acontecido, também segundo Simonsen (1995, p. 130), entre 1968 e 1973, período do "milagre" econômico brasileiro.

Fica configurada neste modelo a indexação tão somente como mecanismo de transmissão da memória inflacionária, bem como a noção de que a capacidade de pagamento de salários reais crescentes por parte de uma economia insere-se no ambiente institucional e estrutural de uma sociedade, não conformando um fenômeno exclusivamente relacionado à oferta e demanda em mercados competitivos, uma vez que "não se pode falar de livre funcionamento dos mercados com indexação compulsória" (Simonsen, 1995, p. 7).

Como se pode depreender da breve revisão acima, a despeito das mensurações de seu grau de significância, persiste a presença da indexação e da inércia inflacionária, sendo indiscutível a sua influência sobre os níveis de preços. Entretanto, o entendimento das causas e das consequências da indexação e da inércia inflacionária exige uma abordagem histórica, para contextualizar a indexação às especificidades políticas e sociais do Brasil, bem como ao pensamento econômico brasileiro a respeito dos determinantes da inflação.

\section{CONFLITO DISTRIBUTIVO, STATECRAFT E A MP DA DESINDEXAÇÃO}

O conflito distributivo emana de uma incompatibilidade entre as aspirações de renda dos indivíduos e o produto dos esforços produtivos acumulados em uma sociedade. Na medida em que a produção e as relações sociais que lhe servem de base estão apoiadas num complexo de normas e regulações salvaguardadas pelo Estado e produzidas pela dinâmica política, o conflito distributivo - como conceito - extrapola o terreno da análise econômica. Neste sentido, propõe-se aqui uma

\footnotetext{
${ }^{10}$ A formulação é tautológica, uma vez que não demonstra a relação de causalidade entre as variáveis. Nas palavras de Simonsen: "O modelo não explica se o que vem primeiro é a galinha ou o ovo, ou seja, se a inflação é causa ou consequência da indexação” (Simonsen, 1995, p. 130).
} 
visão histórica acerca das "constrições habilitadoras" que o regime democrático, em meio a uma conjuntura crítica, impôs à equipe econômica do Plano Real, conferindo maior eficácia, coerência e durabilidade às reformas econômicas pretendidas (Sola, Kugelmas \& Whitehead, 2002, p. 29). A proposta do método é evidenciar as interpenetrações que envolvem as esferas econômica, política e social, demonstrando, com isso, que o Plano Real não foi um transplante imédiato sobre a sociedade das teorias de economistas insulados na burocracia estatal (Diniz, 2000, p. 90). Tentam-se abarcar, ainda que insuficientemente, as interações complexas que emanam das relações Estado-sociedade em diferentes contextos, de estabilidade ou de crise, que conferem riqueza de detalhes, mesmo que com o sacrifício da limpidez da modelagem matemática.

O conceito de statecraft refere-se ao aproveitamento de janelas de oportunidade abertas por crises de governabilidade, em que um agente político, amparado por determinada coalizão de forças políticas, efetua um esforço de reconcentração de recursos de poder que abra caminho para as reformas desejadas. No entanto, este statecrafting apenas se torna possível por conta do "momento crítico" vivido pela sociedade brasileira de pré-anomia, combinado a transformações históricas que vinham efetuando mudanças no mapa cognitivo da sociedade brasileira, o que conduziu a alterações nos critérios de legitimação do poder que, a partir dos anos 1980, priorizavam a estabilização econômica (Sola \& Kugelmas, 2002, p. 100). A anomia a que se dirigia a sociedade brasileira, à beira do abismo hiperinflacionário, gerava incertezas quanto ao futuro da governabilidade, recolocando a estabilização não mais como subproduto das reformas estruturais de caráter liberalizante, mas, antes, como condição ao sucesso das mesmas.

É neste sentido que o Plano Real, a despeito de sua indiscutível genialidade técnica, é antes um instrumento político de apascentamento provisório do conflito distributivo por meio da restauração da credibilidade governamental, condição para o empreendimento de reformas institucionais que podem vir a consolidar um novo padrão de comportamento monetário. ${ }^{11}$ Após numerosas tentativas de estabilização por meio de choques, o ambiente econômico era de profunda incerteza, a qual era gerada pelo próprio governo, de forma que a peça-chave do plano deveria residir na estratégia de comunicação com a sociedade. Mesmo não se valendo de congelamentos, de tablitas, de confiscos, a incerteza quanto ao sucesso do plano no combate a inflação exigia um "seguro" contra uma possível aceleração dos preços (Franco, 1995, p. 149). A viabilidade política do plano passava pela permanência de algum mecanismo de indexação, particularmente

\footnotetext{
${ }^{11}$ A exposição de motivos da MP da desindexação, analisada a seguir, não deixa dúvidas quanto à causalidade estabilização-governabilidade, ao afirmar, em seu ponto 116, que "A implementação firme e segura do Programa de Estabilização Econômica lança, assim, os pilares de uma sociedade mais equânime, capaz de conciliar, nos marcos do regime democrático, os legítimos anseios de desenvolvimento e justiça social” (Ministério da Fazenda, 1994, item 116).
} 
por conta do temor de perdas salariais e de receita tributária na conversão para a nova moeda.

A Exposição de Motivos Interministerial sobre a Medida Provisória que implementa a reforma monetária não deixa dúvidas quanto à persistência da indexação, alegando que a eliminação do instituto da correção monetária "como também o demonstram sucessivas tentativas frustradas de estabilização, não pode dar-se de um só golpe, sob o risco de ampla desorganização das relações econômicas do país" (Ministério da Fazenda, 1994, item 68). Por este motivo, a Medida Provisória restringe o "âmbito de aplicação" da correção monetária baseada em índices de preços, "preservando-a somente ali onde sua manutenção parece ser necessária na atual etapa de reorganização econômica do país, ou seja, no mercado de trabalho, no mercado financeiro e nos contratos de longo prazo" (Ministério da Fazenda, 1994, item 69 - ênfase nossa).

No que se refere ao mercado de trabalho, as normas de correção de salários foram estabelecidas no parágrafo $2^{\circ}$ do art. 29 da Lei $n^{\circ} 8.880$. Ali se assegura aos trabalhadores em geral, no mês da primeira data-base de cada categoria após a primeira emissão da nova moeda, um reajuste de salários em percentual correspondente à eventual variação do IPC-r entre o mês da primeira emissão do Real e o mês imédiatamente anterior à data-base. Na Lei no 8.880, de 27 de maio de 1994, fica claro em seu artigo 17 que

A partir da primeira emissão do Real, o Instituto Brasileiro de Geografia e Estatística - IBGE calculará e divulgará, até o último dia útil de cada mês, o Índice de Preços ao Consumidor, série r - IPC-r, que refletirá a variação mensal do custo de vida em Real para uma população objeto composta por famílias com renda até oito salários mínimos. (Ministério da Fazenda, 1994)

A criação do IPC-r objetivava restringir a proliferação de indexadores que, segundo Franco (1995, p. 149), "trazem informações confusas sobre a inflação que está acontecendo (dólar paralelo, mercados futuros etc.) e cometem erros com muito mais frequência". Os ganhos de capital e preços e salários "errados" que resultam da prática da indexação envolvem realinhamentos grandes que conduzem à aceleração da inflação. A Tabela 1 mostra que o IPC-r seguia de perto o IPCA, ambos calculados pelo IBGE, o que causava preocupações, uma vez que as incertezas dos agentes quanto ao êxito da URV em alinhar os preços gerou um virulento processo de remarcação nos dias que antecederam a conversão para a nova moeda. 
Tabela 1: Índices de Preços — IPC-r e IPCA — IBGE

\begin{tabular}{cccc}
\hline Mês & IPC-r (a) & IPCA (b) & Diferencial (a-b) \\
\hline jul/94 & 6,08 & 6,84 & $-0,76$ \\
ago/94 & 5,46 & 1,86 & 3,6 \\
set/94 & 1,51 & 1,53 & $-0,02$ \\
out/94 & 1,86 & 2,62 & $-0,76$ \\
nov/94 & 3,27 & 2,81 & 0,46 \\
dez/94 & 2,19 & 1,71 & 0,48 \\
jan/95 & 1,67 & 1,70 & $-0,03$ \\
fev/95 & 0,99 & 1,02 & $-0,03$ \\
mar/95 & 1,41 & 1,55 & $-0,14$ \\
abr/95 & 1,92 & 2,43 & $-0,51$ \\
mai/95 & 2,57 & 2,67 & $-0,1$ \\
jun/95 & 1,82 & 2,26 & $-0,44$ \\
\hline Total* & $35,30 \%$ & $33,03 \%$ & $2,27 \%$ \\
\hline
\end{tabular}

Fonte: IBGE

* Variação acumulada em termos compostos no período compreendido entre jul/94 e jun/95

Ademais, "entre as exceções admitidas" pelo item 74 da referida Medida Provisória figura a indexação dos contratos para entrega futura ou de prestação de serviços a serem produzidos, "cujos preços poderão ser reajustados em função do custo de produção ou da variação nos preços dos insumos utilizados, desde que a periodicidade da aplicação desse reajuste seja anual”.

É importante notar que o plano é incompleto também em pontos centrais da estratégia de estabilização. Sicsú (1996) traz ampla amostra de dados evidenciando que os méritos da URV não são aqueles que o plano previa. A "URVerização da economia" não se consolidou conforme o planejado, uma vez que os testes sobre as regras de precificação não evidenciaram "que os empresários consideravam as variações da URV como balizadoras dos reajustes de seus preços” (Sicsú, 1996, p. 84). Como os preços mantiveram-se desequilibrados quando do transplante monetário, caberia à política econômica pós-estabilização conter as pressões por remarcação de preços, sendo a taxa de câmbio valorizada somada ao aprofundamento da abertura comercial o elemento-chave para a contenção dos preços sem qualquer tipo de controle coercitivo (Mollo \& Saad Filho, 2001, p. 40).

Ademais, duas negociações da equipe econômica com a base parlamentar evidenciam os custos políticos do plano. A criação do IPC-r teria sido uma forma de compensar os trabalhadores pelo sucesso da URV em converter os salários pela média (talvez principal mérito deste mecanismo), bem como um "prêmio de risco" contra o fracasso da estabilização, uma vez que o referido índice de preços foi uma concessão à base parlamentar do governo para a aprovação da medida provisória 
que instituía a URV. A UFIR segue a mesma linha, de sendo negociados com a Secretaria da Receita Federal tanto o espaçamento de seu cálculo de semestral a anual quanto a sua posterior extinção (ocorrida no ano 2000) (Bacha, 1998, pp. 41-44).

O "malabarismo político" que foi obrigada a fazer a equipe econômica alcançava o controle de preços dos principais grupos empresariais, oligopólios e monopólios, por meio da chamada "dallarização dos preços", em referência a José Milton Dallari, o principal negociador de preços do governo. Outro aspecto que exigiu enorme desenvoltura da equipe dizia respeito às pressões por aumentos salariais oriundas do setor público, as quais contaram com a aprovação do presidente em exercício, Itamar Franco. Neste sentido, o plano padeceu de sérias deficiências em sua implementação, porque socialmente situado nos quadros do conflito distributivo que emoldurava o jogo político naquele momento crítico da história brasileira.

\section{À GUISA DE CONCLUSÃO: A RECENTE INDEXAÇÃO DE SALÁRIOS}

Adotou-se aqui a hipótese de ser a economia brasileira cronicamente inflacionária. Este expediente se justifica por ter sido o Plano Real orientado por essa premissa, dada a capilaridade da indexação na economia. Assim, pretendeu-se mostrar por que o Plano Real não logrou desindexar a economia por completo, mas tão somente reduzir a velocidade dos reajustes. Se, por um lado, preveniu-se, via legislação, o encurtamento dos intervalos de reajuste (Simonsen, 1995, p. 8), por outro, deu-se ensejo a uma nova modalidade de conflito distributivo, marcado por demandas reprimidas de reajuste com prazos mais dilatados (Mollo \& Saad Filho, 2001), bem como pelo crescente poder de barganha, a partir de 2004, das categorias de trabalhadores de diversos setores da economia, os quais vêm obtendo reajustes dos salários acima da inflação. Estudo do DIEESE mostra que, a partir de 2004, as negociações salariais obtiveram maior sucesso em repor a inflação passada, bem como avançar em seus ganhos reais, como mostra a marca próxima aos $90 \%$ das categorias com atualizações salariais acima da inflação (DIEESE, 2011b, p. 3). ${ }^{12}$

Quando se tomam os setores da economia, os reajustes salariais acima da inflação demonstram generalização por toda a economia, sendo o setor de serviços aquele que obteve maiores índices de reajuste igual ou abaixo do INPC, sugerindo que, nos setores mais beneficiados pela apreciação do câmbio, é reduzido o poder

\footnotetext{
12 Nos estudos realizados entre 1996 e 2008 foram considerados reajustes referentes a um conjunto de categorias profissionais que, ano a ano, formavam um painel diferente. A partir de 2009, o SAS-DIEESE passou a analisar informações de reajustes salariais de categorias pertencentes a um painel fixo, cujo ano base é 2008. No momento, esse painel conta com 845 unidades de negociação dos setores do comércio, da indústria, de serviços e rural (este não analisado na série dos balanços dos reajustes salariais). Desse painel, foram obtidas informações de reajustes salariais de 800 unidades de negociação em 2008; 762 unidades de negociação em 2009; e 700 unidades de negociação em 2010 (cf. DIEESE, 2011b, p. 3).
} 
de barganha dos trabalhadores, por conta da maior oferta de trabalho (DIEESE, 2011b, p. 5).

Neste novo concerto de coisas, como se vê, cada grupo social permanece à espera de condições favoráveis para a reposição de perdas, como é comum em processos de conflito distributivo. Porém, a novidade se manifesta em certa assimetria dos instrumentos de reposição da renda real à disposição de cada grupo; ou seja, alguns setores são impedidos juridicamente de reajustar seus contratos em prazos inferiores a um ano, enquanto outros setores remarcam seus preços sem recurso ao balizamento por qualquer índice, a chamada indexação informal. Permitiu-se, por fim, a indexação de preços em contratos de serviços de utilidade pública, de salários na legislação trabalhista, dos títulos de dívida pública e, mais recentemente, a indexação do salário mínimo por um índice que resulta da soma da taxa de crescimento do PIB de dois anos anteriores (medida de produtividade) e da inflação do ano anterior, medida pelo IPCA-IBGE. Este resíduo de indexação persiste, ainda que domado pelo sistema de metas de inflação, provocando recorrentes alarmes quanto ao risco de retorno da inflação.

Em síntese, a desindexação da economia não foi concluída pelo Plano Real, a despeito do desaparecimento dessa questão do debate público - ao menos até o final da década dos anos 2000. Desde o início da estabilização de preços, os temas mais abordados na agenda pública que trata da política econômica têm sido a questão cambial, o regime de metas de inflação e a responsabilidade fiscal. Ficou relegada a um plano secundário a longeva e resistente prática da indexação no país. Como se buscou mostrar, a meta de desindexar a economia sempre esteve constrita pelo jogo político, que aqui chamamos de statecrafting, o qual premiava a estabilização dos preços como critério de legitimação política, propiciando, assim, a reconcentração dos recursos de poder que permitissem o avanço nas reformas estruturais consentâneas às mudanças históricas na relação Estado-sociedade. Por não se tratar de um fim em si mesma, a meta de desindexação da economia serviu como moeda de troca com o Congresso durante o processo de aprovação da medida provisória que regulamentava a segunda etapa da estabilização, a saber, a URV, obrigando a equipe econômica a fazer concessões à arraigada cultura inflacionária, permitindo a permanência de mecanismos de repasse automático da inflação passada para os preços correntes. É importante levar-se em conta esse aspecto da inflação brasileira, portanto, ao avaliar-se a eficácia da política monetária adotada e as combinações alternativas de instrumentos de estabilização.

\section{REFERÊNCIAS BIBLIOGRÁFICAS}

ARAÚJO, Eurilton; SANTOS, Tatiana Teles (2004) “A dinâmica da inflação brasileira após o Plano Real”, Insper Working Paper, WPE 054, IBMEC: São Paulo, pp. 1-32

ARIDA, Persio; RESENDE, André Lara; ROZENWURCEL, Guillermo; BRUNO, Michael (1986) "Inflação zero: Brasil, Argentina e Israel”, in ARIDA, Persio (org.) Inflação Zero: Brasil, Argentina, Israel, Rio de Janeiro: Editora Paz e Terra. 
BACHA, Edmar (1987) “Moeda, inércia e conflito: reflexões sobre políticas de estabilização no Brasil”. Textos para discussão PUC-RJ, n. 181.

BACHA, Edmar (1998) “O Plano Real: uma avaliação”, in MERCADANTE, Aloizio. O Brasil pós-Real: a política econômica em debate. Campinas, SP: UNICAMP. IE, pp. 11-70.

BANCO CENTRAL DO BRASIL (2011) Relatório de Inflação. Brasília, v. 13, n 1, março, pp. 1-151.

BANCO CENTRAL DO BRASIL (2011) Relatório de Inflação. Brasília, v. 14, nº 2, junho, pp. 1-143.

BARBOSA-FILHO, N. H. (2013) “A Structuralist Inflation Curve”, mimeo. Disponível em: http://www. eesp.fgv.br/sites/eesp.fgv.br/files/file/Nelson \%20Barbosa \%20Structuralist \%20Philips\%20curve\%20v1.pdf. Acesso em 4/12/2013.

BOGDANSGI, J; TOMBINI, A. A.; WERLANG, S. R. (2000) "Implementing inflation targeting in Brazil”, Working Papers Series, Banco Central do Brasil, July: 1-29.

BRESSER PEREIRA, L.C.; NAKANO, Yoshiaki (1984) "Fatores aceleradores, mantenedores e sancionadores da Inflação”. Revista de Economia Política 4(1), janeiro-março: pp. 5-22.

CARVALHO, Fernando J. Cardim (1994) "Reforma monetária, indexação generalizada e o plano de estabilização, Revista de Economia Política, 14 (2), abril-junho: pp. 108-113.

CAMPÊLO, A. K.; CRIBARI-NETO, F. (2003) “Inflation inertia and 'inliers': the case of Brazil”. Revista Brasileira de Economia, 57 (4): pp. 713-719.

CHRISTIANO, L.; EICHENBAUM, M.; EVANS, C. (2005) "Nominal rigidities and the dynamic effects of a shock to monetary policy", Journal of Political Economy, 113, pp. 1-45, 2005.

CRIBARI-NETO, F.; CASSIANO, K. (2005) "Uma análise da dinâmica inflacionária brasileira”, Revista Brasileira de Economia, 59 (4): pp. 535-566.

DELFIM NETTO, A. (2011) "Voto de confiança". Jornal Valor Econômico — Suplemento Novos rumos da economia brasileira, 2.5.2011.

DIEESE (2011a) “Análise dos atuais componentes da inflação no Brasil”. Nota Técnica, no. 98, maio de 2011. Disponível online: www.dieese.org.br. Acesso em 19.5.2011.

DIEESE (2011b). "Balanço das negociações dos reajustes salariais em 2010”, Estudos e Pesquisas, 55, março de 2011. Disponível online: www.dieese.org.br. Acesso em 19.5.2011.

DINIZ, Eli (2000) Globalização, reformas econômicas e elites empresariais: Brasil anos 1990. Rio de Janeiro: Editora FGV.

DORNBUSCH, Rudiger (1997) "Brazil's incomplete stabilization and reform”. Brookings Papers on Economic Activity, Volume 28, Issue 1, pp. 367-404.

FIGUEIREDO, Erik Alencar; MARQUES, André M. (2009) "Inflação inercial como um processo de longa memória: análise a partir de um modelo Arfima-Figarch”. Estudos Econômicos, São Paulo, 39 (2), abril-junho: pp. 437-458.

FISCHER, Stanley (1977) "Wage indexation and macroeconomic stability", Carnegie-Rochester Conference Series on Public Policy, Elsevier, vol. 5(1), pages 107-147, January.

FREITAS, P.S.; MINELLA, A.; RIELLA, G. (2002) "Metodologia de cálculo da inércia inflacionária e dos efeitos do choque dos preços administrado". Notas Técnicas do Banco Central do Brasil, Brasília, n. 22, julho: pp. 1-14.

FRAGA NETO, Armínio (1985) "Indexation and inflation in Brazil”, Textos para discussão PUC-RJ, n. 96.

FRANCO, Gustavo (1995) O Plano Real e outros ensaios, Rio de Janeiro: Editora Francisco Alves.

FRANCO, Gustavo (2005) “Auge e declínio do inflacionismo no Brasil”, in Giambiagi, Fabio, André Villela, Lavinia Barros de Castro e Jennifer Hermann, Economia Brasileira Contemporânea (1945-2004). Rio de Janeiro: Elsevier Editora.

GIAMBIAGI, Fabio (1988) "Salário, inflação e conflito distributivo: reflexões acerca da escala móvel", Revista de Economia Política, 8 (3), julho-setembro: pp. 73-87.

GOODFRIEND, M.; KING, R. (1997) "The new neoclassical synthesis and the role of monetary policy”, in Bernake, B., Rotemberg, J. (eds.), NBER Macroeconomics Annual 1997. Cambridge: MIT Press, pp. 231-283.

GRAY, Jo Anna (1976) “Wage indexation: a macroeconomic approach”, Journal of Monetary Economics (2). 
HIRSCHMAN, Albert O. (1961) A Estratégia do Desenvolvimento Econômico. Rio de Janeiro: Fundo de Cultura.

KIRSTEN, José Tiacci (2013) “A indexação está de volta na classe média”, Informações FIPE, agosto, pp. 13-14.

LIMA, Gilberto Tadeu; SETTERFIELD, Mark (2008) "Inflation targeting and macroeconomic stability in a Post Keynesian economy", Journal of Post Keynesian Economics 30 (3.435): pp. 435-461.

LOPES, F. L. (1985) "Inflação inercial, hiperinflação e desinflação: notas e conjecturas”, Revista de Economia Politica, 5 (3): pp. 135-151.

MAIA, A.; CRIBARI NETO, F. (2006) "Dinâmica inflacionária brasileira: resultados de auto-regressão quantílica”, Revista Brasileira de Economia, 60 (2): pp. 153-165.

MARTINEZ, Thiago Sevilhano; CERQUEIRA, Vinicius dos Santos (2011) "Estrutura da inflação brasileira: determinantes e desagregação do IPCA”, Texto para Discussão IPEA, n. 1634, Rio de Janeiro, julho.

MODIANO, E. (1983) “A dinâmica de salários e preços na economia brasileira: 1966-1981”, Pesquisa e Planejamento Econômico, 15 (1): pp. 39-68.

MODIANO, E. (1985) "Salários, preços e cambio: os multiplicadores dos choques numa economia indexada", Pesquisa e Planejamento Econômico, 15 (1).

MODIANO, E. (1988) Inflação: inércia e conflito. São Paulo: Campus.

MOLLO, M. L.; SAAD FILHO, Alfredo (2001) "Reconhecimento social da moeda: observações sobre a inflação e a estabilização de preços no Brasil", Revista de Economia Política, 21 (2), abril-junho: pp. 24-42.

RESENDE, A. L. (1979) “Incompatibilidade distributiva e inflação estrutural”, Textos para discussão PUC-RJ, n. 1.

RESENDE, A. L. (1985) “A moeda indexada: uma proposta para eliminar a inflação inercial”, Revista de Economia Política, 5 (2): pp. 130-134.

ROWTHORN, Robert (1977) "Conflict, inflation and money", Cambridge Journal of Economics, 1 (3): pp. 215-239.

SEGURA-UBIERGO, Alex (2012) “The puzzle of Brazil's high interest rates”, IMF Working Paper WP/12/62, 2012.

SIMONSEN, Mário Henrique (1995) 30 Anos de Indexação. Rio de Janeiro: Editora FGV. (1974) A Nova Economia Brasileira. Rio de Janeiro: José Olympio.

SINGER, Paul (1988) "Inflação e mercado como sistemas alternativos de regulação", Estudos Avançados (USP), 2(3): pp. 77-87.

SOLA, Lourdes; KUGELMAS, Eduardo; WHITEHEAD, Laurence (2002) Banco Central, autoridade política e democratização: um equilíbrio delicado. Rio de Janeiro: Editora FGV.

SOLA, Lourdes; KUGELMAS, Eduardo (2002) "Estabilidade econômica e o Plano Real como construção política: statecraft, liberalização econômica e democratização”, In SOLA, Lourdes, KUGELMAS, Eduardo, WHITEHEAD, Laurence: pp. 79-109

TAYLOR, Lance (1983) Structuralist Macroeconomics. Nova Iorque: Basic Books.

TAYLOR, Lance (2004) Reconstructing macroeconomics: Structuralist proposals and critiques of the mainstream. Cambridge, Massachusetts: Harvard University Press.

TEJADA, C.; PORTUGAL, M. (2001) “Credibilidade e inércia inflacionária no Brasil: 1986-1998”, Estudos Econômicos, 31 (1): pp. 459-494..

TOMBINI, A. S.; ALVES, S. A. L. (2006) “The recent Brazilian disinflation process and costs”, Working Paper Series, n. 109, Central Bank of Brasil.

VERA, Leonardo (2005) “Can recession feed inflation? A conflicting claims framework", Review of Political Economy, Volume 17, Number 4, 1-19, October. 